\title{
SOCIAL TRANSFERS AND INCOME INEQUALITY IN BULGARIA
}

Svilena Mihaylova, Silviya Bratoeva-Manoleva

\section{Abstract}

The paper analyzes the distributional effects of social transfers in Bulgaria in the period 2000-2014, using income inequality decomposition by factor components. The results suggest that social transfers mitigate income inequality, but this effect varies depending on the type of transfer. Pensions exert the strongest influence due to their significant share in total income, which also rises over time. Family allowances are pro-poor in nature, but because of their small share in beneficiaries' total income, their impact on overall inequality is much weaker. "Other social benefits" have the weakest inequality-reducing effect, which is due to their higher concentration towards the richest decile and increasing share in total income. Despite the inequalitydecreasing impact of social transfers, we argue that they should not be regarded as the sole remedy for the sharp income disparities in the country, but need to be accompanied by relevant active labor market policies.

Key words: social transfers, income inequality, redistribution

JEL classification: $138, H 55, D 31$

\section{INTRODUCTION}

The determinants and consequences of high income inequality have become one of the most debated topics among academics and policy makers in the aftermath of the last global economic crisis. The social and economic costs of high income inequality are largely recognized and there is a widespread view that a certain level of government intervention is needed to tackle extreme income disparities, poverty and social exclusion. However, differences remain in the perceptions of the extent of such intervention and the adequate tools for its implementation. Therefore, understanding the distributional effects of various social policy instruments is not only of academic interest, but also has important practical implications.

As in most post-socialist economies, the market transition in Bulgaria has been accompanied by a rise in income inequality: from 22.8 in 1990, the country's Gini coefficient increased to 30.4 in 2014 according to the National Statistical Institute. Based on Eurostat data, which are compiled through a different methodology and allow comparison with other countries, Bulgaria has even higher inequality (35.4), which is the third largest in the European Union (EU) in 2014. At the same time, the country has the lowest GDP per capita among member states, limited social protection

Svilena Mihaylova, $\mathrm{PhD}$

Assistant Professor

Department of Economics

University of Economics - Varna

E-mail: s.mihaylova@ue-varna.bg

Silviya Bratoeva-Manoleva, $\mathrm{PhD}$

Assistant Professor

Department of Economics

University of Economics - Varna

E-mail: smanoleva@ue-varna.bg 
expenditures and faces adverse demographic trends, as well as persistent labor market problems. All of these issues undoubtedly pose challenges to the social policy of the country and its capacity to alleviate existing income disparities. Therefore, the question of how social transfers affect income inequality in Bulgaria is particularly relevant in terms of policy choices. Given its weak presence in the literature, it requires the attention of researchers. Taking this into account, the present paper aims to explore the distributional effects of social transfers in Bulgaria in the period 2000-2014 by using an income inequality decomposition method proposed by Pyatt, Chen and Fei (1980). In conducting the analysis we are led by the understanding (also found in Barr (2004) and Niehues (2010)) that it is very important to make a distinction between the different categories of social benefits with regard to their impact on income inequality. We reckon that unveiling how each type of social transfer manifests its distributional effect will provide deeper insight into the current role and the future opportunities of social policy in the country.

The rest of the paper is organized as follows: Section 2 provides a summary of the literature on the relationship between social transfers and income inequality. Section 3 describes briefly the main features of the social protection system in Bulgaria. Section 4 presents the methodology used in the analysis. Section 5 discusses the empirical results and Section 6 concludes the paper.

\section{LITERATURE REVIEW}

The impact of social policy on income distribution has generated much debate among social scientists and policy makers. The widespread view of the existence of a trade-off between equity and efficiency has been central to this debate for a long time. On the one hand, market forces alone do not necessarily provide a desirable income distribution with regard to equity, which is seen as a justification for government intervention through redistribution. On the other hand, many economists reckon that redistributive policies, used to alleviate income inequality, hamper efficiency and growth. However, this trade-off has been recently revisited as some studies find that redistribution and the induced reduction in inequality are associated with higher and more durable growth (Ostry, Berg and Tsangarides 2014).

With regard to the success of social policies in fighting inequality and poverty, there has been also a longstanding controversy in the welfare state literature over the question of whether social transfers should be targeted to the most needy or universal. On the one side there are those who believe that a welfare state can only mitigate inequality and poverty effectively and efficiently when benefits are mainly targeted to those most in need, i.e. when benefits are selective. The underlying argument is that selective benefit systems are cheaper, entail lower taxes and are more conducive to economic growth, which benefits the poor directly (Marx, Nolan and Olivera 2015). However, several lines of counter-arguments have been established against targeting. First, there are important dysfunctions of means-testing - higher administrative costs compared to universal benefit systems, higher nontake up partly because of stigmatization issues and decreasing incentives to work leading to poverty traps (Van Oorschot 2002). Second, in contrast with universal benefit systems, selective welfare systems have less political support for redistribution and therefore fewer resources available for redistributive policies. As a result, the redistributive role of such systems tends to be weaker.

The comparison of the two types of welfare systems forms the core of the highly influential "Paradox of Redistribution" proposed by Korpi and Palme (1998). According to the authors, selective systems that strongly target resources towards the poorest, paradoxically, have a smaller redistributive impact than universal systems, whereas the latter, while being least distributive on paper, distribute in fact the most.

The far-reaching importance of the distributional impact of social policies has led to the emergence of many empirical studies. One can distinguish between two approaches in the literature regarding the distributional role of welfare systems (Fuest, Niehues and Peichl 2010). The first approach compares pre-socialspending income inequality with post-transfers inequality. More specifically, it sequentially applies different benefit instruments and compares the resulting income distribution with the counterfactual distribution without the benefit in question. The majority of studies that have used this approach find substantial inequality-decreasing effects of social transfers (for example, Immervoll et al. (2006); Whiteford (2008) and Fuest, Niehues and Peichl (2010)). However, as noted by Niehues (2010), this standard approach of measuring redistribution is problematic because it neglects the fact that social benefits have behavioral second-order effects, which infuence the distribution of market incomes before government intervention. If benefit levels discourage recipients from taking part in the labor market at all, this leads to an increase in the unemployment rate, which in turn also worsens pre-transfer income inequality. Taking these effects into account, Niehues (2010) finds that more social 
spending effectively reduces inequality. However, this result is mainly due to unemployment benefits and public pensions, whereas more targeted benefits do not significantly reduce income inequality because of their substantial disincentive effects. Furthermore, Sinn (1995) even finds an inequality-enhancing role of social transfers due to increased investment in risky assets and moral hazard effects induced by higher social spending. Hence, more redistribution may result not only in more pre-transfer but also in more posttransfer inequality.

The second approach in measuring the distributional impact of social transfers is the factor source decomposition technique suggested by Rao (1969), Pyatt, Chen and Fei (1980) and Shorrocks (1982). It allows calculating the contribution of each social transfer to overall inequality simultaneously. This approach has been used in a number of cross-national and individual country studies. For example, Milanovic (1999) applies this method to analyze income inequality in six transition economies (Bulgaria, Hungary, Latvia, Poland, Russia and Slovenia) over the period 1987 - 1995. With respect to social transfers, he finds that pensions have increased inequality in Central Europe, while non-pension transfers were too small and two poorly focused to make much difference. In a study on the impact of cash social transfers on inequality in thirteen EU member-states, Heady, Mitrakos and Tsakloglou (2001) find that the distributional effect of these transfers is greater in countries that spend a higher proportion of income on them, but that there are other important determinants, including the distribution of funds between different types of transfers and the degree of targeting for each transfer.

As for studies at the individual country level, Koutsampelas (2011) examines the distributional impact of social transfers in Cyprus and finds that all transfers redistribute income, but this effect varies depending on the type of transfer. Family benefits and "other benefits" have the smallest redistributive effect, whereas public assistance and child benefits have the strongest. In a study for Turkey, Baslevent (2014) also finds varying distributional effects of the different types of social transfers. Social assistance and disability benefits alleviate income inequality, whereas the redistributive impact of pension payments and unemployment benefits does not appear to be very large, since especially the latter are received mainly by individuals who are outside the lower end of the income distribution. Studying the redistributive role of the social welfare system in Greece, Mitrakos (2014) finds evidence of an inequality-reducing effect of transfers. Medeiros and Souza (2015) examine inequality in Brazil and their results suggest that the pension system in the country is slightly inequality-increasing. While social assistance transfers tend to mitigate inequality, this effect is minimal because of their minor share in total income.

Bulgaria, as a post-socialist economy that has experienced a rise in inequality during its transition, has also attracted the interest of researchers in the field of social policy and distribution. For example, Hassan and Peters (1995) find that the social safety net in Bulgaria is not well targeted - most social benefits are found to be pro-poor, in the sense that they improve income distribution, but many benefits accrue to better-off households as well. Kotzeva (1999) finds that while in 1992 social transfers reduced inequality, in 1996 they turned into a driver of income inequality and their contribution to the overall Gini coefficient was around $6 \%$. Nikolova et al. (2011) examine the impact of public policy on income inequality in Bulgaria during the period 1992-2006. Using income inequality decomposition and regression analysis, the authors find that unemployment benefits and child allowances are the main social payments reducing inequality among Bulgarian households. Comparing Gini coefficients before and after social transfers, Tzanov et al. (2013) find that this policy instrument prevents a drastic increase in the ratio between the incomes of the poor and the rich social groups in Bulgaria. The authors outline several reasons for the growing importance of the role of social transfers: an aging population, the increase in the number of persons of retirement age, the emigration of the young and educated, rising unemployment rate and crisis trends during the examined period.

To sum up, the prevailing finding in the empirical literature is that social transfers mitigate income inequality. However, recent studies distinguishing in detail between the distributional effects of the various types of social transfers in Bulgaria are relatively scarce. Therefore, we focus on examining this issue, but as a starting point we first outline the main features of the Bulgarian social protection system.

\section{THE BULGARIAN SOCIAL PROTECTION SYSTEM}

The social protection system in Bulgaria encompasses both contributory social insurance schemes and noncontributory social assistance benefits and social service programs. Social insurance (contributory) programs include old age, disability and survivor pensions, sickness and healthcare benefits. There are also active and passive labor market policies, including training, employment incentives and unemployment 
and early retirement benefits. Social assistance (noncontributory) programs include monthly family allowances, housing and heating allowances, social pensions for the elderly, disability benefits, last resort social assistance programs and numerous other small benefits. Social insurance programs account for the largest share of total expenditure on social protection, while social assistance programs constitute a very small part (International Monetary Fund 2014).

The distinction between contributory and noncontributory programs is important because of the different distributional effects that they tend to exert. While the amount of social insurance benefits depends mainly on past contributions of individuals, likely making their redistributive effect small, social assistance benefits are typically means-tested (i.e. provided on the basis of an income test) and thus are expected to have a larger redistributive impact. With the purpose of studying the distributional effects of various types of social transfers, in the present paper we focus on those included in total income, namely: social insurance, social assistance benefits, and, from labor market measures, unemployment benefits.

The state and development of the social protection system in Bulgaria in the last 26 years have been under the influence of the social and economic changes taking place in the country since the start of the market transition. The first years of the transition process were marked by output drop, rising unemployment, high inflation and increasing social tension. Key liberalization, privatization and restructuring processes were strongly influenced by an uncontrolled struggle of interests. Specific to these processes was the accumulation of wealth in a few hands and its appropriation for unproductive and speculative purposes (Nenovsky and Koleva 2002). Together with market reforms, this led to a significant rise in income inequality and poverty in the first years of transition.

Bulgaria entered the market transition process with a universal social protection system inherited from the previous regime that faced a number of challenges in the new reality: the fact that the state was no longer the sole provider of employment and insurance; high and persistent unemployment in contrast to full employment under socialism; the emergence of various forms of economic activity and 2000-2014

Source: Eurostat the development of an informal sector; and the erosion of the principles of solidarity between generations (Tzanov et al. 2012). Although the existing system was inadequate, there was political pressure for its maintenance in the first years of transition, which led to further income disparities.

Until 1996 the dominant measures for social protection were unemployment benefits and social aid, which were clearly passive measures. Unemployment prevention was implemented through subsidizing non-profitable state enterprises or early retirement, which led to a significant rise in the proportion of pensioners in the working-age population. However, since 1996-1997, when the country experienced a severe economic crisis, there has been an increase in the importance of active measures aimed at stimulating labor participation (Tache and Neesham 2011). The introduction of a currency board in 1997 led to macroeconomic stabilization and marked the beginning of a period of high economic growth, decreasing unemployment and massive foreign direct investment inflows, which lasted until the economic recession in 2009. However, the fiscal discipline imposed by the currency board and the convergence criteria in relation to the EU accession in 2007 restricted the room for implementing robust social protection. This is evident in the decreasing levels of government social protection expenditure as a percentage of GDP during the period of favorable economic development until 2008. As seen in Figure 1, the share of government expenditure on social protection in GDP fell from $12.8 \%$ in 2000 to $10.1 \%$ in 2007.

Figure 1: Government expenditure on social protection (\% of GDP) in Bulgaria,

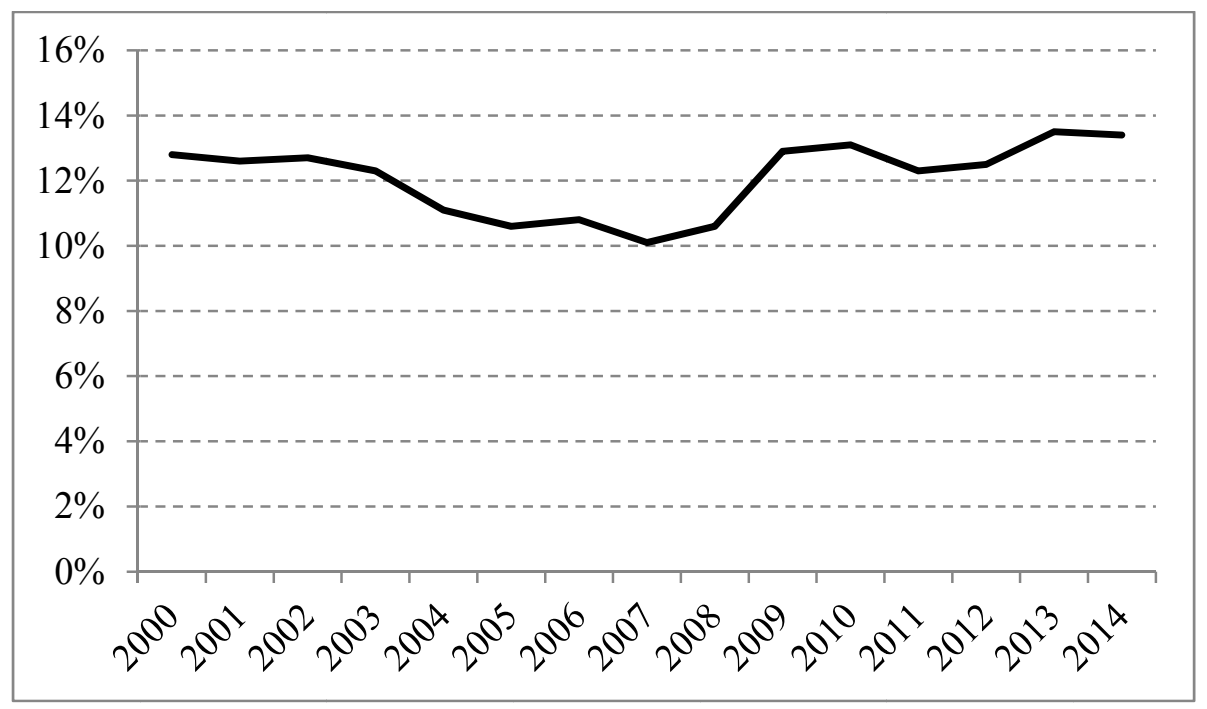


After the country was hit by the global economic crisis, social transfers were frozen in the period 2010-2011. Slight budget-neutral increases in targeted social protection were approved in 2013. The first aid package increased assistance to households that were most affected by the crisis and focused on employment and energy assistance measures. The emphasis of the second was on child and heating allowances.

Among all social protection benefits, those related with old age have the largest share, followed by sickness and healthcare benefits. As shown in Figure 2, in 2014 old age social benefits constituted $44 \%$ of total social benefits, while the share of sickness and healthcare benefits was $27.6 \%$. The prevalence of those two types of social benefits is due to an unfavorable demographic structure, the aging of the population and the deterioration of its health status.

Compared to other EU members, Bulgaria has one of the lowest shares of social protection expenditure in GDP, which is the reason why some authors such as Drahokoupil and Myant (2010) put the country in the category of a "minimal welfare state model". As noted by Tache and Neesham (2011), the welfare system in Bulgaria during the transition period cannot be approximated by any particular type of "classical" welfare regimes such as the liberal, corporatist and social-democratic regimes, proposed by EspingAndersen (1990) or the Mediterranean (Southern) regime, subsequently suggested by other authors (for example, Ferrera 1996). According to Tache and Neesham (2011) the welfare system in Bulgaria is of a mixed type because it displays characteristics of various welfare regimes. As far as funding is concerned, the Bulgarian welfare system is more similar to the liberal type. In terms of benefit and service coverage, it resembles the social-democratic type. However, if one considers workplace-related status differentials in benefit provision, as well as the preference for a social insurance based system, then the welfare system is closer to the corporatist type. The important role of the family in welfare provision makes the system similar to the Mediterranean type.

It is a common view and an established empirical finding that countries that spend more on social protection have lower levels of income inequality and poverty. Although there are a variety of factors affecting income distribution, higher social spending reflects the capacity of a country to influence the level of inequality. As seen in Figure 3, Bulgaria and Romania, along with the Baltic countries, spend the least on social protection and also have the highest levels of income inequality in the EU by Gini coefficient. On the contrary, countries such as Denmark and Finland, where social protection benefits as a percentage share in GDP are the highest, have significantly lower income disparities.

Figure 2: Structure of social protection benefits by function in Bulgaria, 2014

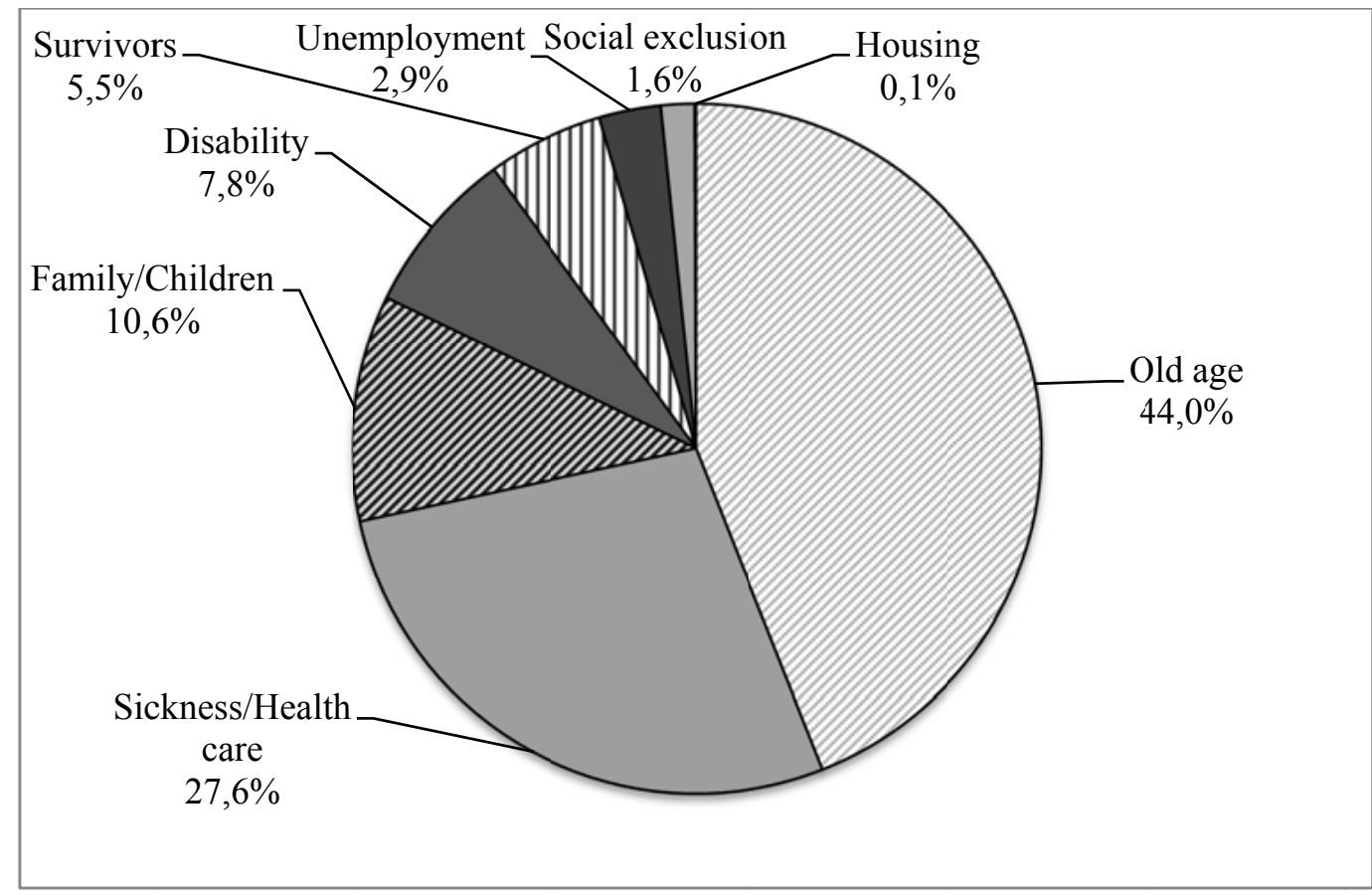

Source: Eurostat 
Figure 3: Social protection benefits (\% of GDP) and income inequality in the EU, 2014

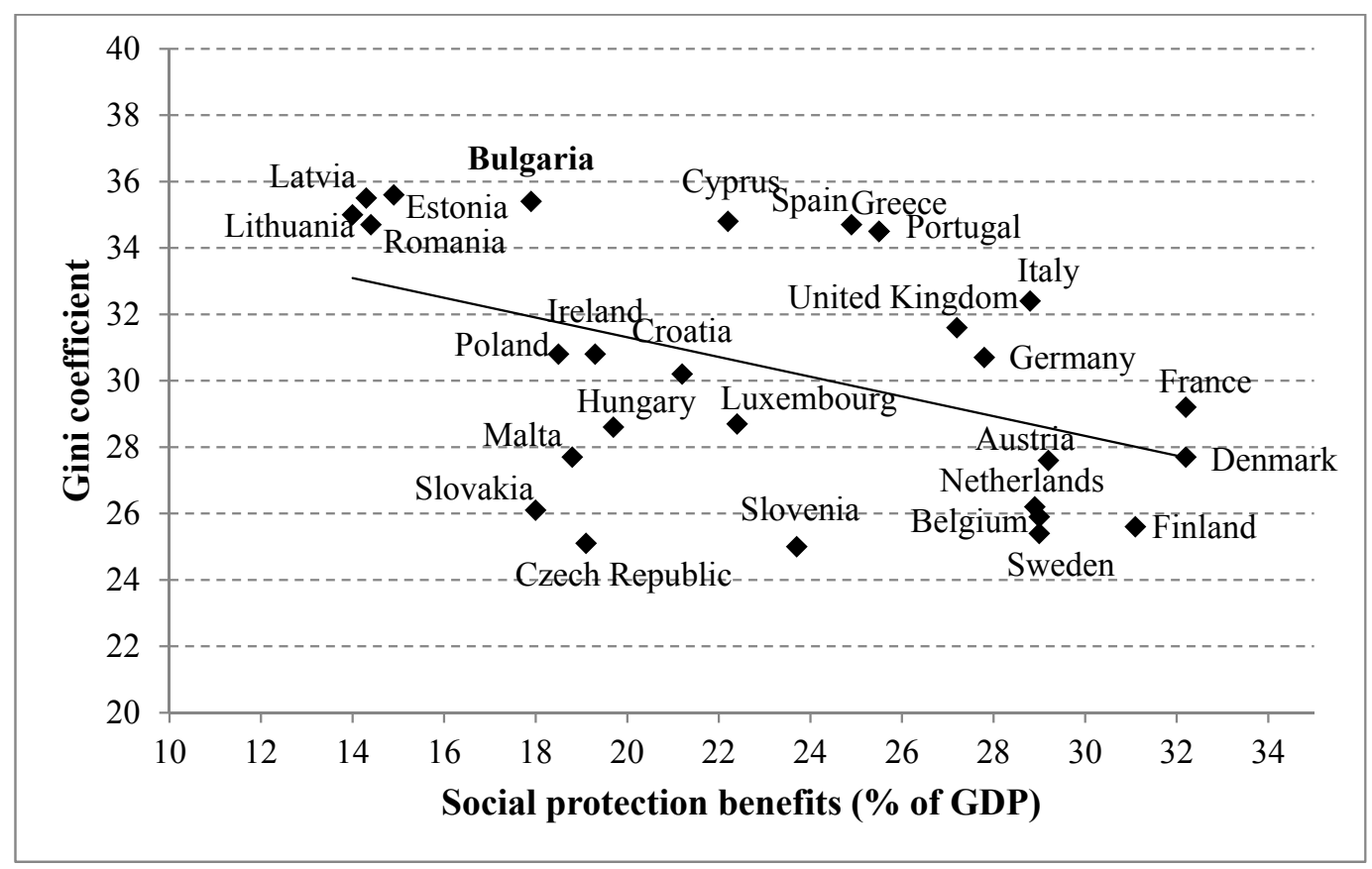

Source: Eurostat

Besides having one of the highest levels of income inequality in the EU, Bulgaria also faces adverse demographic trends (an aging population, negative population growth and a high mortality rate), structural unemployment, low labor force participation ratio and substantial regional social and economic disparities. Addressing these problems is of vital importance with respect to promoting sustainable development and inevitably brings up the question of the type of social policy instruments that would be most appropriate to achieve this goal. These issues are of far more than just academic interest and have significant practical implications, which are also evident in the National program for development of Bulgaria until 2020. Tackling poverty, inequality and social exclusion are some of its main priorities, which focus on providing sustainability and adequacy of social transfers, as well as active labor market polices.

\section{METHODOLOGY}

The data used for the empirical research were drawn from household budget surveys compiled by the National Statistical Institute. We use average per capita total household income by sources and decile groups for the period 2000-2014. The data on social transfers are grouped into four main categories: unemployment benefits, pensions, family allowances and "other social benefits". The latter includes sickness and healthcare benefits, disability benefits, housing and heating allowances, last resort social assistance and numerous other small benefits.

The methodology is based on Pyatt, Chen and Fei (1980), who have proposed one of the most extensively used methods for income inequality decomposition by factor components. As illustrated by the authors, overall inequality depends on the differentiation of each income source, the extent of correlation between the income of each source and total income and the share of each income source in total income.

In order to estimate the inequality of distribution of the various social transfers and their impact on overall income inequality, we use concentration curves. These curves show the distribution of a certain social transfer when recipients are ranked by total income. When the concentration curve of a social transfer is above the Lorenz curve, this type of transfer reduces income inequality. The further the concentration curve is above the Lorenz curve, the stronger the inequality-decreasing effect. Conversely, if the concentration curve is below the Lorenz curve, this type of transfer contributes to an increase in income inequality. If the concentration curve crosses the Lorenz curve, the social transfer has a mixed impact on overall income inequality, i.e. in some segments of the income distribution it has an equalizing effect and in others it promotes greater inequality (Bishop and Formby 1994).

From a concentration curve a concertation coefficient can be obtained. It has the following formula:

$$
C\left(\frac{z}{t}\right)=\frac{2 \operatorname{cov}(z, r(t))}{n \bar{z}}
$$


where $C(z / t)$ is the concentration coefficient, $z$ is the amount of a certain social transfer, $\bar{z}$ is its mean, $t$ is total income, $\operatorname{cov}(z, r(t))$ is the covariance between $z$ and the ranking of the recipient according to total income $(r(t))$ and $n$ is the number of observations.

The concentration coefficient shows how evenly a social transfer is distributed over total income. It ranges from -1 when all transfers are received by the poorest individual through 0 when all individuals receive the same amount of transfer, to 1 when all transfers are received by the richest individual. When the concentration coefficient is 0 , the concentration curve coincides with the $45^{\circ}$ line of perfect equality. When the concentration coefficient is lower than the Gini coefficient, this type of transfer reduces income inequality and the concentration curve is located above the Lorenz curve. Conversely, when the concentration coefficient of a social transfer is larger than the Gini coefficient, it has an inequality-increasing effect and the concentration curve lies below the Lorenz curve. Furthermore, the concentration coefficient can take negative values, which suggest that the social transfer has not only an inequality-reducing effect, but that it is also more concentrated among the poorest individuals.

Next, by using the concentration coefficients, we calculate the elasticity of the Gini coefficient with respect to a proportional change in each social transfer:

$$
E_{i}=S_{i} \cdot g_{i}-S_{i}
$$

where $E_{i}$ is the elasticity of the Gini coefficient with respect to social transfer $i, S_{i}$ is the share of social transfer $i$ in total income, and $g_{i}$ is the relative concentration coefficient of social transfer $i$. The latter is calculated as a ratio between the concentration coefficient of social transfer $i$ and the overall Gini coefficient:

$$
g_{i}=\frac{C_{i}}{G}
$$

If $g_{i}$ is greater (or lower) than 1 , ceteris paribus, an equiproportionate increase in social transfer $i$ will cause an increase (or decrease) in aggregate inequality. As for elasticity, if it is greater than 0 , an increase in social transfer $i$ is associated with an increase in income inequality. If $E_{i}<0$, social transfer $i$ mitigates income inequality.

\section{EMPIRICAL RESULTS}

For the purposes of studying the distributional effects of the various types of social transfers, first we examine the distribution of each transfer by decile group. As illustrated in Table 1, the most unevenly allocated transfers are family allowances: $27.1 \%$ of them are concentrated in the poorest decile, whereas the richest decile receives only 3.3\%. "Other social benefits" are also unequally distributed but in favor of the richest income group, which receives $29 \%$ of this type of transfer against only $6 \%$ for the poorest decile. The social transfers with the most equal distribution are unemployment benefits.

Next, we continue with a calculation of the shares of each transfer in total income by decile group. As illustrated in Table 2, social transfers in general have the greatest importance for the four poorest deciles (their shares in total income range between 45.5\% and $46.4 \%)$. On the contrary, social transfers are only $12.4 \%$ of the total income of the richest decile. When looking at the importance of the different types of social transfers, it is evident that pensions have the highest share in total income for all decile groups. For most deciles unemployment benefits have the lowest share in total income, followed by family allowances.

\begin{tabular}{|c|c|c|c|c|c|c|c|c|c|c|}
\hline \multirow{2}{*}{ Types of social transfers } & \multicolumn{10}{|c|}{ Decile groups } \\
\hline & 1 & 2 & 3 & 4 & 5 & 6 & 7 & 8 & 9 & 10 \\
\hline Pensions & 3.3 & 7.6 & 9.8 & 11.3 & 12.3 & 12.2 & 11.9 & 11.6 & 11.2 & 8.9 \\
\hline Unemployment benefits & 8.7 & 12.5 & 7.2 & 7.2 & 8.7 & 11.8 & 12.9 & 11.4 & 11.4 & 8.0 \\
\hline Family allowances & 27.1 & 15.1 & 12.2 & 11.1 & 8.7 & 8.5 & 7.1 & 3.5 & 3.5 & 3.3 \\
\hline "Other social benefits" & 6.0 & 5.7 & 6.6 & 8.5 & 7.3 & 8.5 & 11.2 & 9.5 & 7.7 & 29.0 \\
\hline Total transfers & 4.3 & 7.8 & 9.6 & 11.0 & 11.7 & 11.8 & 11.7 & 11.2 & 10.7 & 10.2 \\
\hline
\end{tabular}

Table 1: Distribution of social transfers by decile groups, 2014 (\%)

Source: Authors' calculations based on data from "Household budgets in the Republic of Bulgaria" (2014), National Statistical Institute 
Table 2: Social transfers as a percentage of total income by decile groups, 2014

\begin{tabular}{|c|c|c|c|c|c|c|c|c|c|c|}
\hline \multirow{2}{*}{ Types of social transfers } & \multicolumn{10}{|c|}{ Decile groups } \\
\hline & 1 & 2 & 3 & 4 & 5 & 6 & 7 & 8 & 9 & 10 \\
\hline Pensions & 30.8 & 39.7 & 41.2 & 40.8 & 39.1 & 34.3 & 29.2 & 24.6 & 19.6 & 9.4 \\
\hline Unemployment benefits & 1.7 & 1.4 & 0.6 & 0.6 & 0.6 & 0.7 & 0.7 & 0.5 & 0.4 & 0.2 \\
\hline Family allowances & 8.6 & 2.7 & 1.8 & 1.4 & 1.0 & 0.8 & 0.6 & 0.3 & 0.2 & 0.1 \\
\hline "Other social benefits" & 4.8 & 2.6 & 2.4 & 2.7 & 2.0 & 2.1 & 2.4 & 1.8 & 1.2 & 2.7 \\
\hline Total transfers & 45.9 & 46.4 & 46.1 & 45.5 & 42.7 & 37.9 & 32.9 & 27.1 & 21.4 & 12.4 \\
\hline
\end{tabular}

Source: Authors' calculations based on data from "Household budgets in the Republic of Bulgaria" (2014), National Statistical Institute

In order to quantify the distributional effects of the different types of social transfers, we turn to the income inequality decomposition technique described in the previous section. Figure 4 shows the concentration curves of all social transfers, as well as the Lorenz curve.

All concentration curves (with the exception of "other social benefits") are above the Lorenz curve, which suggests that social transfers mitigate income inequality. This effect is the strongest in the case of family allowances as seen from the position of their curve, which lies at the highest distance from the Lorenz curve. This effect is due to the fact that family allowances are concentrated mostly in the poorest deciles. Conversely, "other social benefits" exert the weakest inequality-reducing impact, as their concentration curve is the most closely located with respect to the Lorenz curve. However, it should be noted that in the last decile this concentration curve falls below the Lorenz curve, which means that in this segment of the distribution "other social benefits" deepen income inequality. This could be explained by the higher share of the richest decile in this type of social transfer (29\%) than their corresponding share in total income (24.4\%). As for pensions and unemployment benefits, they are the most equally distributed as shown by the proximity of their concentration curves to the line of equality, suggesting the lack of a strong pro-poor distributional effect. This finding could be explained by the insurance-based nature of these two types of

Figure 4: Concentration curves of different types of social transfers, 2014

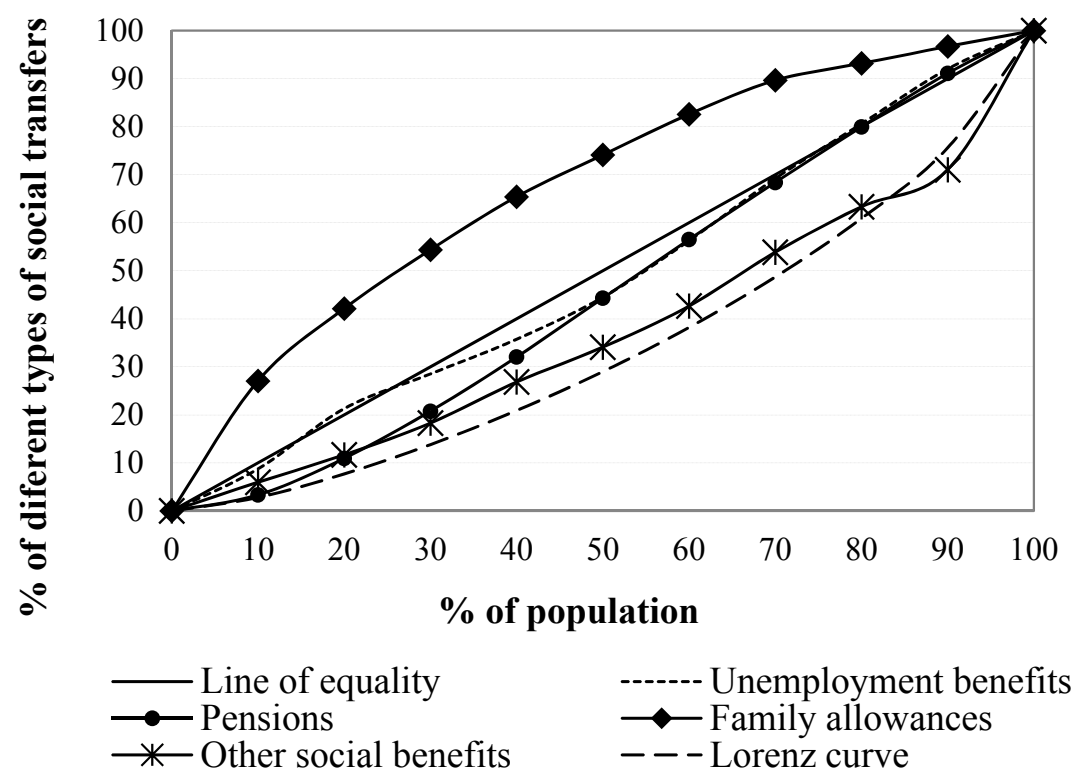

Source: Authors' calculations based on data from "Household budgets in the Republic of Bulgaria" (2014), National Statistical Institute 
transfers, which aim at maintaining previous status and income rather than redistributing from the rich to the poor.

In order to examine how the distributional effect of social transfers changes over time we calculate their concentration coefficients for the period 2000-2014.

As Table 3 shows, the concentration coefficients of all social transfers in all years are lower than the corresponding Gini coefficients, which suggests that all types of transfers mitigate income inequality. However, this effect is most pronounced in the case of family allowances as confirmed by their negative concentration coefficient. As seen by its change within the examined period, the inequality-reducing impact of this type of transfer gets stronger over time. Unemployment benefits also mitigate income inequality, but their effect weakens as shown by the change in the sign of their concentration coefficient. As for pensions, their concentration coefficient decreases over time, which means that they become more equally distributed among decile groups. Conversely, the concentration coefficient of "other social benefits" increases, suggesting that their inequality-reducing impact weakens and that they tend to favor mainly the higher income groups of the population.

The results discussed above show that all social transfers play a role in alleviating income inequality, but to estimate the strength of their influence we calculate the elasticity of the Gini coefficient with respect to each social transfer.

As shown in Table 4, the elasticities of all social transfers have negative signs, meaning that an increase in any would lead to a reduction in income inequality. The overall inequality-decreasing effect of social transfers becomes more pronounced over time as suggested by the increase of their elasticities (in absolute terms). The results for 2014 show that a $10 \%$ increase in total social transfers would lead to a decline

Table 3: Concentration coefficients of social transfers, 2000-2014

\begin{tabular}{|l|c|c|c|c|c|c|c|c|}
\hline & \multicolumn{7}{c|}{ Concentration coeffcicients } \\
\hline Types of social transfers & 2000 & 2002 & 2004 & 2006 & 2008 & 2010 & 2012 & 2014 \\
\hline Pensions & 0.147 & 0.148 & 0.152 & 0.098 & 0.048 & 0.145 & 0.077 & 0.085 \\
\hline Unemployment benefits & -0.031 & -0.058 & -0.193 & -0.121 & -0.094 & -0.145 & 0.045 & 0.026 \\
\hline Family allowances & -0.053 & -0.139 & -0.225 & -0.222 & -0.226 & -0.236 & -0.265 & -0.350 \\
\hline "Other social benefits" & 0.018 & 0.132 & 0.228 & 0.157 & 0.208 & 0.169 & 0.251 & 0.244 \\
\hline Total transfers & 0.126 & 0.133 & 0.141 & 0.091 & 0.059 & 0.131 & 0.078 & 0.083 \\
\hline Gini coefficient & 0.310 & 0.342 & 0.339 & 0.304 & 0.295 & 0.291 & 0.312 & 0.304 \\
\hline
\end{tabular}

Source: Authors' calculations based on data from “Household budgets in the Republic of Bulgaria" (2000-2014), National Statistical Institute

Table 4: Share in total income (\%) and elasticities of social transfers, 2000-2014

\begin{tabular}{|c|c|c|c|c|c|c|c|c|}
\hline Types of social transfers & 2000 & 2002 & 2004 & 2006 & 2008 & 2010 & 2012 & 2014 \\
\hline & \multicolumn{8}{|c|}{ Share in total income (\%) } \\
\hline Pensions & 21.4 & 20.1 & 22.2 & 22.6 & 23.2 & 30.9 & 26.7 & 25.8 \\
\hline Unemployment benefits & 1.1 & 0.8 & 0.4 & 0.4 & 0.2 & 0.6 & 0.7 & 0.5 \\
\hline Family allowances & 0.8 & 0.5 & 0.7 & 0.7 & 0.7 & 0.9 & 0.8 & 0.9 \\
\hline "Other social benefits" & 1.2 & 1.6 & 1.6 & 2.0 & 3.1 & 1.8 & 1.9 & 2.3 \\
\hline \multirow[t]{2}{*}{ Total transfers } & 24.5 & 23.0 & 24.8 & 25.6 & 27.1 & 34.3 & 30.0 & 29.5 \\
\hline & \multicolumn{8}{|c|}{ Elasticity } \\
\hline Pensions & -0.113 & -0.114 & -0.122 & -0.154 & -0.194 & -0.156 & -0.201 & -0.186 \\
\hline Unemployment benefits & -0.012 & -0.010 & -0.007 & -0.005 & -0.002 & -0.009 & -0.006 & -0.005 \\
\hline Family allowances & -0.009 & -0.007 & -0.011 & -0.012 & -0.012 & -0.016 & -0.015 & -0.019 \\
\hline "Other social benefits" & -0.011 & -0.010 & -0.005 & -0.010 & -0.009 & -0.008 & -0.004 & -0.004 \\
\hline Total transfers & -0.146 & -0.141 & -0.145 & -0.180 & -0.217 & -0.189 & -0.225 & -0.214 \\
\hline
\end{tabular}

Source: Authors' calculations based on data from “Household budgets in the Republic of Bulgaria” (2000-2014), National Statistical Institute 
in income inequality by $2.14 \%$.

Pensions exert the strongest inequality-decreasing effect, as their elasticity is the highest in absolute value. Based on data for 2014, if the amount of pensions rises with $10 \%$, income inequality would decrease by $1.86 \%$. Furthermore, their influence deepens over time despite the lack of pro-poor targeting. This is due to the fact that pensions have the highest share in total income and this share also experiences the most significant increase under the examined period (from $21.4 \%$ in 2000 to $25.8 \%$ in 2014 ) due to the aging of the population.

Compared to pensions, the elasticities of the other social transfers are significantly lower, suggesting that their inequality-reducing effect is weaker. For example, the elasticity of unemployment benefits in 2014 is -0.005 , meaning that if they increase by $10 \%$, overall income inequality would be reduced by $0.05 \%$. The decrease of the elasticity of this transfer (in absolute terms) from 2000 to 2008 shows that its impact diminishes over time. This could be explained by the declining share of unemployment benefits in total income (from $1.1 \%$ in 2000 to $0.2 \%$ in 2008 ) during the pre-crisis period of macroeconomic stability, high economic growth and lowering unemployment rate. In the years following the economic crisis the share of unemployment benefits in total income rises and their concentration coefficient turns positive, which together explain the slight increase in their elasticity.

The elasticity of "other social benefits" varies within a similar range as unemployment benefits. The results for 2014 show that an increase in "other social benefits" by $10 \%$ would cause a reduction of the Gini coefficient by $0.04 \%$. This type of social transfer has the weakest inequality-reducing effect, which is due to its higher concentration towards the richest decile and its increasing share in total income.

As for family allowances, the results for 2014 suggest that if this transfer increases by $10 \%$ it would lead to a reduction in income inequality by $0.19 \%$. Moreover, their elasticity shows an upward trend (in absolute terms). This strengthening of the inequalitydecreasing effect of family allowances is due to their pro-poor distribution, which also becomes more pronounced over time. It is worth noting that family allowances exert this influence despite the fact that their share in total income is stable during the examined period. The pro-poor distributional effect of family allowances is explained by the fact that they are means-tested and are targeted towards individuals whose income is below a certain level. However, it is worth noting that although family allowances have the largest share in social assistance programs and the highest number of beneficiaries, their efficiency has been subject to criticism. The main arguments regarding this relate to the lack of differentiation of family allowances with regard to social status and financial situation, as well as their formal nature and loose control - less than $1 \%$ of the monthly allowances are suspended because of lack of regular school attendance (Institute for Market Economics 2015). Therefore, if measures are undertaken to tackle these problems, the pro-poor distributional effect of family allowances revealed above could be even higher, contributing to a stronger inequality-reducing effect and in the end to an improved efficiency for this type of social assistance.

A key task of an efficient social protection system is enabling individuals to quickly leave the programs they benefit from, rather than just achieving a sustained and long-term mitigation of the negative consequences of social exclusion. This brings up the question of whether the social protection system stimulates beneficiaries to start a job or creates disincentives for work. This problem is particularly relevant for the lowest income groups, where unemployment benefits and social assistance payments have the highest importance - in 2014 they constitute 15\% of the total income of the poorest decile in contrast to only $3 \%$ for the richest. Moreover, the past and potential future earnings of the lowest income deciles are very often likely to be lower than currently received social transfers. This serves as a disincentive for starting a job and creates unemployment traps. Therefore, although social transfers have an inequality-decreasing effect, their provision should be accompanied by relevant active labor market policies.

\section{CONCLUSION}

The paper explores the distributional effects of different types of social transfers in Bulgaria in the period 2000-2014, using an income inequality decomposition method. The main empirical finding is that social transfers mitigate income inequality, which is in line with the results from previous studies for other countries. Looking at the distributional effects of each social transfer provides a more detailed picture of the role that the social protection system plays in inequality reduction. While pensions and unemployment benefits are the most equally distributed among deciles, family allowances are increasingly pro-poor and "other social benefits" are highly concentrated towards the richest decile. With regard to the strength of the inequality-reducing effect, pensions exert the strongest influence due to their significant share in total income, which also rises over time. As for family allowances, 
which have the highest share in social assistance benefits, they are pro-poor in nature, but because of their small share in beneficiaries' total income, their impact on overall inequality is much weaker.

It has to be noted that despite the revealed inequality-reducing effect of social transfers, they have to be used with caution as a social policy tool for tackling income disparities. Taking into account some important country-specific factors such as limited resources for social protection, fiscal discipline considerations, an aging population and low economic activity, it becomes clear that public discussions cannot focus on social transfers as the only remedy for high income inequality. Their use should be accompanied by the implementation of crucial active labor market policies, such as increasing labor force participation and the quality of human resources. Furthermore, efforts should be directed towards achieving better targeting of social transfers, since this would lead to an improved efficiency and a stronger inequality-reducing effect of the social protection system. Given the findings of the paper, future research in the field of social policy in Bulgaria might focus on exploring whether the redistributive outcomes of various social transfers are offset by possible behavioral disincentive effects.

\section{REFERENCES}

Barr, N. 2004. The Economics of the Welfare State. Oxford University Press.

Baslevent, C. 2014. Social Transfers and Income Inequality in Turkey: How Informative Is the Survey of Income and Living Conditions. Ekonomi-tek - International Economics Journal 3 (3): 23-42.

Bishop, J. A. and Formby, J. P. 1994. A Dominance Evaluation of the Distribution of Income and the Benefits of Economic Growth in the Unites States. In The Changing Distribution of Income in an Open U.S. Economy, edited by J. Bergstrand, T. Cosimano and R. Sheehan, 69-103. Amsterdam: North Holland.

Drahokoupil, J. and Myant, M. 2010. Varieties of Capitalism, Varieties of Vulnerabilities: Financial Crisis and its Impact on Welfare States in Eastern Europe and the Commonwealth of Independent States. Historical Social Research 2 (35): 266-295.

Esping-Andersen, G. 1990. The Three Worlds of Welfare Capitalism. New Jersey: Princeton University Press.

Eurostat database, http://ec.europa.eu/eurostat

Ferrera, M. 1996. The 'Southern' Model of Welfare in Social Europe. Journal of European Social Policy 6 (1): 17-37.
Fuest, C., Niehues, J. and Peichl, A. 2010. The Redistributive Effects of Tax Benefit Systems in the Enlarged EU. Public Finance Review 38 (4): 473-500.

Hassan, F. M. A. and Peters, R. K. 1995. Social Safety Net and the Poor during the Transition: The Case of Bulgaria. World Bank Policy Research Working Paper No. 1450, Washington DC: World Bank.

Heady, C., Mitrakos, T. and Tsakloglou, P. 2001. The Distributional Impact of Social Transfers in the European Union: Evidence from the ECHP. Fiscal Studies 22 (4): 547-565.

Household budgets in the Republic of Bulgaria (2000-2014). Sofia: National Statistical Institute.

Immervoll, H., Levy, H., Lietz, C., Mantovani, D., O'Donoghue, C., Sutherland, H., and Verbist, G. 2006. Household Incomes and Redistribution in the European Union: Quantifying the Equalizing Properties of Taxes and Benefits. In The Distributional Effects of Government Spending and Taxation, edited by D. B. Papadimitriou, 135-165. New York: Palgrave Macmillan.

Institute for Market Economics 2015. Challenges Faced by Social Assistance in Bulgaria. Sofia: Institute for Market Economics.

International Monetary Fund 2014. Bulgaria: Selected Issues Paper. IMF Country Report No. 12/24, Washington DC: International Monetary Fund.

Korpi, W. and Palme, J. 1998. The Paradox of Redistribution and Strategies of Equality: Welfare State Institutions, Inequality, and Poverty in the Western Countries. American Sociological Review 63 (5): 661-687.

Kotzeva, M. 1999. Opportunities for Studying the Factor Determination of the Income Differentiation of the Population. Statistics 1: 3-15 (in Bulgarian).

Koutsampelas, C. 2011. Social Transfers and Income Distribution in Cyprus. Cyprus Economic Policy Review 5 (2): 35-55.

Marx, I., Nolan, B. and Olivera, J. 2015. The Welfare State and Anti-Poverty Policy in Rich Countries. In Handbook of Income Distribution, edited by A. Atkinson and F. Bourguignon, 2063-2139, vol. 2B. Amsterdam: Elsevier.

Medeiros, M. and Souza, P. H. G. F. 2015. State Transfers, Taxes and Income Inequality in Brazil. Brazilian Political Science Review 9 (2): 3-29.

Milanovic, B. 1999. Explaining the Increase in Inequality during Transition. Economics of Transition 7 (2): 299-341.

Mitrakos, T. 2014. Inequality, Poverty and Social Welfare in Greece: Distributional Effects of Austerity. Working Papers 174, Bank of Greece.

Nenovsky, N. and Koleva, D. 2002. Bulgaria: Socio-Economic Developments since 1990. In The Social Impact of Informal Economies in Eastern Europe, edited by R. Neef and M. Stanculescu, 49-56. Ashgate. 
Niehues, J. 2010. Social Spending Generosity and Income Inequality: A Dynamic Panel Approach. IZA Discussion Papers 5178, Institute for the Study of Labor (IZA).

Nikolova, S., Markov, N., Nikolov, B. and Dochev, N. 2011. Inequality and Public Policy: A Country Study for Bulgaria. Working Papers 095, Centre for Economic and Strategic Research, The wiiw Balkan Observatory.

Ostry, J.D., Berg, A. and Tsangarides, C. G. 2014. Redistribution, Inequality, and Growth. IMF Staff Discussion Notes 14/02, Washington DC: International Monetary Fund.

Pyatt, G., Chen, C. and Fei, J. 1980. The Distribution of Income by Factor Components. Quarterly Journal of Economics 95 (3): 451-473.

Rao, V. M. 1969. Two Decompositions of Concentration Ratio. Journal of the Royal Statistical Society 132 (3): 418-425.

Shorrocks, A. F. 1982. Inequality Decomposition by Factor Components. Econometrica 50 (1): 193-211.

Sinn, H.-W. 1995. A Theory of the Welfare State. Scandinavian Journal of Economics 97 (4): 495-526.

Tache, I. and Neesham, C. 2011. The Performance of Welfare Systems in Post-Communist Europe: the Cases of Romania and Bulgaria. International Journal of Economics and Research 2: (5) 90-107.

Tzanov, V., Ivanova, P., Panteleeva, S. and Bogdanov, S. 2013. GINI Country Report: Growing Inequalities and their Impacts in Bulgaria. GINI Country Reports, AIAS, Amsterdam Institute for Advanced Labor Studies.

Tzanov, V., Shopov, G., Beleva, l., Hristoskov, Y. and Lukanova, P. 2012. Labor Market and Social Protection in the Economic Development of Bulgaria 1990-2011. ERIBAS Books, Bulgarian Academy of Sciences - Economic Research Institute, No. 11, 1-332 (in Bulgarian).

Van Oorschot, W. 2002. Targeting Welfare: on the Functions and Dysfunctions of Means-testing in Social Policy. In World Poverty: New Policies to Defeat an Old Enemy, edited by P. Townsend and D. Gordon, 171-193. Bristol: The Policy Press.

Whiteford, P. 2008. How Much Redistribution Do Governments Achieve? The Role of Cash Transfers and Household Taxes. In Growing Unequal: Income Distribution and Poverty in OECD Countries, edited by OECD, 97-121. Paris: OECD Publishing. 